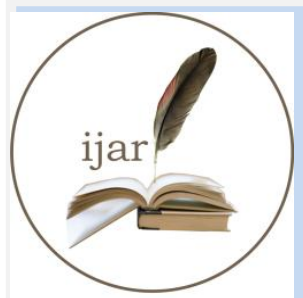

ISSN NO. 2320-5407
Journal Homepage: - www.journalijar.com INTERNATIONAL JOURNAL OF ADVANCED RESEARCH (IJAR)

Article DOI: $10.21474 / \mathrm{IJAR} 01 / 1431$

DOI URL: http://dx.doi.org/10.21474/IJAR01/1431

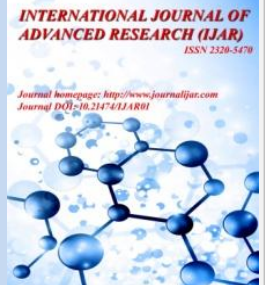

RESEARCH ARTICLE

\title{
IMMUNOGENICITY OF SALIVARY GLAND AND MIDGUT HOMOGENATE ANTIGENS AGAINST CAMEL TICK HYALOMMA DROMEDARII (IXODOIDEA: IXODIDAE) AND RELATED BIOLOGICAL IMPACTS AND CONTROL POTENTIAL : IN VIVO STUDY.
}

\author{
Walaa Ahmed Moselhy ${ }^{1}$, Aly Fahmy El-Sayed ${ }^{2}$, Fatma El-Sayed Ali ${ }^{1}$, Eman Ahmed El-Kelesh ${ }^{3}$, Wesam \\ Soliman Ebrahim ${ }^{1}$ and Abd El-Baset Badr El-Din Zayed ${ }^{1}$. \\ 1. Zoology Department- Faculty of Science - Al-Azhar University (Girls branch). \\ 2. VACSERA- Egypt. \\ 3. Parasitology Department, Animal Health Research Institute, Dokki, Giza, Egypt.
}

\section{Manuscript Info}

.....................

Manuscript History

Received: 12 June 2016

Final Accepted: 19 July 2016

Published: August 2016

Key words:-

Immunization, salivary gland, midgut, Western blot, ELISA, SDS-PAGE, Hyalomma dromedarii.

\section{Abstract}

Salivary gland $(\mathrm{SgAg})$ and midgut $(\mathrm{MgAg})$ antigens derived from partially fed female $H$. dromedarii were used to vaccinate rabbits at a dose of $100 \mu \mathrm{g} / \mathrm{kg}$ protein. The immunized hosts were challenged with unfed female ticks. Data revealed a significantly decreased feeding percent and duration, engorged tick and egg mass weights, number of eggs laid, hatching percent and fertility compared to control groups. Overall vaccine efficacy was evaluated as $67 \%$ and $43.79 \%$ for $\mathrm{SgAg}$ and $\mathrm{MgAg}$, respectively, that means tick Ags used induced best protection against $H$. dromedarii population. Immunogenicity of experimental vaccine homogenates revealed a strong and specific immune response against both antigens. Western blot analysis revealed that 7 polypeptide bands ranging in their molecular weights from 95.8 to $32.3 \mathrm{kDa}$ were recognized in $\mathrm{SgAg}$, whereas 10 polypeptide bands ranging from 93.7 to $8.6 \mathrm{kDa}$ were identified in $\mathrm{MgAg}$.

\section{Introduction:-}

Ticks are important ectoparasites of domestic animals (Roberts \& Janovy, 2005). In Egypt, Hyalomma dromedarii is an important pest of livestock parasitizing chiefly camels and sometimes attack man. As they feed for extended periods of time on their hosts, they cause substantial economic loss to camel production through anaemia, toxicoses and severe physical damage to hides (Ibrahim et al., 2001). This tick species plays an important role in transmitting haemoprotozoan disease, bovine tropical theileriosis (Bhattacharyulu et al., 1975) and camel theileriosis and babesiosis (Mazyad \& Khalaf, 2002). The idea of developing immuno-based prophylactic measures against tick infestations is based on the concept that ticks feed on immunized hosts may ingest antibodies specific for a target antigen(s) within the tick, thereby exerting deleterious effects on feeding and reproduction (Allen \& Humphreys, 1979; Pruett, 1999). Trager (1939a) observed the development of natural resistance to Dermacentor variabilis after a single infestation of the host. Several researchers attempted to induce immune resistance by the inoculation of the host with different tick extracts. Salivary glands are employed for vaccination as they appear intuitively as an obvious source of naturally exposed antigens injected by the tick into the host during feeding (Mulenga $\boldsymbol{e t}$ al., 1999). However, successful immunization of hosts against tick infestations using gut and other non-salivary extracts

Corresponding Author:- Walaa Ahmed Moselhy.

Address:- Zoology Department- Faculty of Science - Al-Azhar University (Girls branch). 
(Concealed antigens) of ticks was assessed for the first time by Allen \& Humphreys (1979). Concealed antigens are preferred over exposed ones since natural antigens were supposed to have co-evolved with the host and lost part of their antigenicity (Tellam et al., 1992), mediated largely by immediate type hypersensitivity (Willadsen, 1987) and the vaccine that caused allergy would be undesirable. However, their limitations are many such as they does not prevent feeding of ticks, therefore, does not stop the damage to the hides or the transmission of the tick-borne pathogens. Moreover, immunity conferred by them is not boosted by natural infestations like natural antigens, and require periodic revaccination especially in endemic areas (Sahibi et al., 1997). So that, identification of potent antigens especially those exposed ones in order to overcome these limitations must continue. Literature dealing with the immunization of hosts with tick-derived salivary gland and midgut reports their great interference with feeding and reproductive performances of females belonging to various species (Allen \& Humphreys, 1979; Brown and Askenase, 1986; Manohar and Banerjee, 1992; Kumar and Kumar, 1995; Sahibi et al., 1997; Szabó and Bechara, 1997; Jittapalapong et al., 2000 \& 2004; Abdel-Shafy et al., 2008; Asif et al., 2011). The present study was undertaken to assess the induced effects in the tick $H$. dromedarii after feeding on hosts injected by three subcutaneous inoculations of $100 \mu \mathrm{g} / \mathrm{kg}$ protein of both $\mathrm{SgAg}$ and $\mathrm{MgAg}$ on 0, 14 and 28 day. The work includes the main biological parameters affecting reproduction and development such as feeding period, amount of ingested blood, oviposition, hatchability and fertility. The dose was further used to investigate the humoral immune response (Total $\mathrm{IgG}$ ) and to determine the immunoreactive protein bands in both tested antigens following their fractionation.

\section{Materials and methods:-}

Tick origin and colonization:-

Engorged $H$. dromedarii females collected from infested camels at Imbaba market, Giza governorate, Egypt were used to start a colony in the Parasitology Department laboratories, Animal Health Research Institute, Dokki, Giza, Egypt. The rabbit Oryctolagus cuniculus (2.5-3 kg weight) not previously attacked with ticks and free from coccidian infection was used as a host. Ticks were kept at $28 \pm 1{ }^{\circ} \mathrm{C}$ and relative humidity of $75 \%$ as described by Berger et al. (1971).

\section{Preparation of salivary gland and midgut antigens:-}

Salivary gland and midgut tissues from approximately 200 semi-fed $H$. dromedarii females were prepared. Living semi-fed females were washed with 0.01 M Phosphate-buffered saline (PBS, pH 7.2) and embedded in a Petri-dish containing a mixture of paraffin wax and charcoal. The dorsal integument of the tick was removed and the internal organs were immersed with PBS. Salivary glands and midgut were removed, placed in cold PBS $\left(4^{\circ} \mathrm{C}\right)$ and stored at $-20^{\circ} \mathrm{C}$. They were subsequently thawed and sonicated by an ultra-sonicator in ice bath at $55,000 \mathrm{cycle} / \mathrm{sec}$ five times, one minute each, followed by one minute as cooling interval. The extracts were centrifuged at $4^{\circ} \mathrm{C}$ for $1 \mathrm{~h}$ at 14000 rpm, using high speed cooling centrifuge, according to Heller-Haupt et al. (1996). The resulting supernatant of each tissue was separated and used as antigenic material. The protein content of $\mathrm{SgAg}$ and $\mathrm{MgAg}$, was measured using the micro total protein (MT-P) Pyrogallol-Red kit (Egyptian company for Biotechnology (S.A.E).

\section{Immunization:-}

Rabbits were artificially immunized against $H$. dromedarii tick infestation according to the protocol of artificial immunization (Sran et al., 1996). Rabbits were divided into 4 groups, ( $3 /$ each). Group I was kept as negative control, group II inoculated with aluminium hydroxide adjuvant (Alum) while groups III and IV inoculated with $\mathrm{MgAg}$ and $\mathrm{SgAg}$, respectively. Rabbits of groups III and IV received three subcutaneous inoculations of $100 \mu \mathrm{g} / \mathrm{kg}$ protein (Abdel-Shafy $\boldsymbol{e t}$ al., 2008) emulsified with Alum in equal volumes. The first immunization dose was administered on day 0 post emulsification with Alum. The second and third doses were given on days 14 and 28 respectively same as the first dose. On the other hand, group II received three inoculations of $1 \mathrm{ml}$ PBS with an equal volume of Alum at the same days as groups III and IV. On day 36 post-immunization, rabbits were infested with adult unfed $H$. dromedarii ticks. The infestation was carried out using 10 males and 10 females per rabbit. Daily observation was performed to detect some biological parameters of females.

\section{Biological parameters:-}

The biological performance of females was examined by determination of their feeding percent and period, oviposition, hatchability and fertility. Feeding $\%$ was determined by dividing the number of fed females / total number of females $x$ 100. Feeding period is the time taken from starting feeding to engorgement. The amount of blood ingested by females was determined by the weight prior to feeding subtracted from the weight directly post feeding. Oviposition was represented by oviposition percent (number of ovipositing females / total number of females x100), pre-oviposition period (days from engorgement to onset of egg laying), and the number of eggs for 
the oviposited female. Hatchability was represented by the pre-hatching period (days from onset of egg laying to onset of hatching) and hatching percent (number of hatched eggs / total number of eggs X100). Fertility is the weight of egg mass divided by the weight of replete female (Khalil et al., 1984) in addition to the weight of one egg (Weight of egg mass/Total number of eggs). The efficiency of the tested vaccines was assessed by determining the number of engorged females (\%DT), the egg laying capacity (\%DO) and the efficacy (\%E) (Galaï et al., 2012) where $\% \mathrm{DT}=100\left[1-\left(\frac{N T V}{N T C}\right)\right]$ (NTV is the mean number of engorged females collected from vaccinated groups and NTC is the mean number of engorged females collected from the control group), \%DO $=100\left[1-\left(\frac{\text { PATV }}{\text { PATC }}\right)\right]$ (PATV is the average weight of eggs per replete female of the vaccinated groups and PATC is the average weight of eggs per replete female of the control group) and $\% \mathrm{E}=100[1-($ CRT $x$ CRO $)$ ] [CRT is the reduction in the mean number of females in vaccinated groups compared to the control group (NTV/NTC) and CRO is the reduction in the egg laying capacity of vaccinated females compared to the control group (PATV/PATC)].

\section{Immune response:-}

Blood samples were collected weekly from the ear vein of rabbits from all groups till the $7^{\text {th }}$ week postimmunization. Sera were separated, aliquoted and stored at $-20^{\circ} \mathrm{C}$ till use. The antibody levels against $\mathrm{SgAg}$ and $\mathrm{MgAg}$ were measured using indirect ELISA technique according to Voller et al. (1976) with some modifications. Initially, a checkerboard titration was used to optimize the reaction conditions regarding the sensitizing antigen concentration, antibody and conjugate dilutions. Post optimization, the tested antigens were applied in a

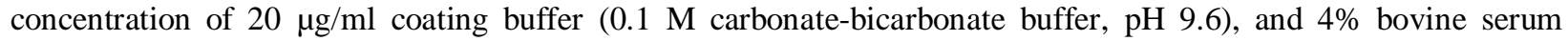
albumin (BSA) in PBS buffer was used to block nonreactive sites on the microtiter plates. Serum samples were dispensed in triplicates and the starting dilution of sera samples was 1:100 prepared in 1\% BSA/PBS, while anti rabbit conjugate was used as $1 / 1000$ in $1 \%$ BSA/PBS. Ortho-phenylene diamine (OPD) was used as a substrate and allowed to react in the dark at room temperature for 15-20 minutes. The reaction was stopped with $1 \mathrm{~N}_{2} \mathrm{SO}_{4}$ and optical density (OD) was measured at $450 \mathrm{~nm}$ by ELISA reader (BioRad, USA).

\section{Polyacrylamide Gel Electrophoresis (SDS-PAGE):-}

Electrophoretic analysis of $\mathrm{SgAg}$ and $\mathrm{MgAg}$ was performed using the Mini-Protein II Dual-Slab Cell (BioRad, USA) and 10\% SDS-PAGE under reducing conditions according to the method described by Laemmli, 1970. Protein bands were visualized by Commassie blue stain.

\section{Western blot analysis:-}

The profile of reactive bands of the tested antigens was recognized by hyperimmune sera collected from rabbits on day 36-post primary immunization. The electrophoresed antigens were transferred from gels to nitrocellulose membranes for immunoblotting using a Bio-Rad Semi-dry transfer cell according to the manufactures protocol. Membranes were cut into $0.5 \mathrm{~cm}$ stripes, blocked with 5\% skim milk/PBS-Tween and probed with rabbit anti-sera 1:100 diluted for $1 \frac{1}{2} \mathrm{~h}$ over a shaker at room temperature. After four wash cycles with hot PBS-Tween $\left(65^{\circ} \mathrm{C}\right)$, membranes were incubated with anti-rabbit IgG peroxidase conjugate at a dilution of 1:500 in 5\% skim milk/PBSTween. After three wash cycles with hot PBS-Tween $\left(65^{\circ} \mathrm{C}\right)$ and two times with PBS alone, chromogen DAB/PBS$30 \% \mathrm{H}_{2} \mathrm{O}_{2}$ was added to the nitrocellulose stripes for 10-15 minutes allowing the colorimetric reaction to develop. The reaction was stopped using distilled $\mathrm{H}_{2} \mathrm{O}$ and visualized by the naked eye.

\section{Statistical analysis:-}

Data were statistically analyzed by SAS (2004) using general linear model procedure (GLM) classification, followed by Duncan Multiple Range Test to examine the significance between means.

\section{Results:-}

Immunization of rabbits using $\mathrm{MgAg}$ and $\mathrm{SgAg}$ affected markedly the ability of females to attach and feed. It resulted in a substantial reduction $(\mathrm{P}<0.01)$ in the feeding percentage to $83.33 \%$ and $70 \%$, respectively, versus $100 \%$ and $95 \%$ of negative control and Alum-inoculated groups [Table 1]. On the other hand, the time required for full engorgement was significantly reduced $(\mathrm{P}<0.05)$ post immunization. The shortest feeding period was observed in group IV being 6.21 days compared with the other groups recording $6.94,6.73$ and 6.44 days for groups I, II and III, respectively. The amount of blood ingested by females fed on immunized rabbits exhibited a significant decrease $(\mathrm{P}<0.01)$ compared to those fed on unvaccinated one. Females of groups III and IV ingested 633.50 and 572.00 
$\mathrm{mg}$, respectively, whereas those of the control ones (I and II) consumed 868.63 and $774.33 \mathrm{mg}$ respectively [Table $1]$.

Table 1:- Effects of salivary gland and midgut antigens on feeding percent, feeding period and amount of ingested blood by female $H$. dromedarii.

\begin{tabular}{|c|c|c|c|c|}
\hline Biological parameter & Group I & Group II & Group III & Group IV \\
\hline Feeding percent $\% \pm \mathrm{SE}$ & $100.00 \pm 4.082^{\mathrm{a}}$ & $95.00 \pm 4.082^{b}$ & $83.33 \pm 4.082^{c}$ & $70.00 \pm 4.082^{d}$ \\
\hline $\begin{array}{l}\text { Feeding period (day) } \\
\quad(\text { Mean } \pm \text { SE) }\end{array}$ & $6.94 \pm 0.15^{\mathrm{a}}$ & $6.73 \pm 0.15^{a b}$ & $6.44 \pm 0.14^{b c}$ & $6.21 \pm 0.16^{c}$ \\
\hline $\begin{array}{c}\text { Ingested blood volume (mg) } \\
(\text { Mean } \pm \text { SE) }\end{array}$ & $868.63 \pm 40.41^{\mathrm{a}}$ & $774.33 \pm 41.74^{a}$ & $633.50 \pm 38.10^{b}$ & $572.00 \pm 43.20^{b}$ \\
\hline
\end{tabular}

* Group I: Negative control, Group II: Alum-inoculated rabbits, Group III: MgAg-immunized rabbits and Group IV: SgAg-immunized rabbits.

* Figures followed by the same letters are statistically similar $(\mathrm{p}>0.05)$; those followed by different letters are significantly different $(\mathrm{p}<0.05-\mathrm{p}<0.01)$.

Fully engorged females were collected, weighed and put individually in glass vials, then placed in an incubator and checked daily for egg laying. The ratio of ovipositing females was $100 \%$ in groups I and II, which decreased significantly $(\mathrm{P}<0.01)$ to $76.6 \%$ and $60 \%$ in groups III and IV, respectively. No significant difference was observed in the preoviposition period among the different groups. Salivary gland antigen-immunized group only exhibited a significant prolongation $(\mathrm{P}<0.05)$ in their prehatching period being 23.5 days compared with the negative control group which recorded 22.17 days. On the other hand, females fed on rabbits immunized with $\mathrm{SgAg}$ have the most prolonged oviposition time being 24.62 days which decreased to 23.55, 22.87 and 22.33 days in MgAg-immunized, Alum-inoculated and negative control groups, respectively. Meanwhile, the number of eggs laid by females and the hatching percent decreased significantly $(\mathrm{P}<0.01)$ as a result of immunization by both antigens [Table 2]. The mean weights of replete females, egg masses laid and fertility were presented in table (3). Data revealed that all these parameters decreased significantly as a result of immunization of rabbits with the tested antigens. The mean weight of replete females of group III $(754.55 \mathrm{mg})$ was statistically similar $(\mathrm{P}>0.05)$ to those of group II $(782.67 \mathrm{mg})$. On the other hand, it differed significantly $(\mathrm{P}<0.01)$ when compared to the negative control which recorded $877.50 \mathrm{mg}$. The lowest mean weight $(651.25 \mathrm{mg})$ of replete females was observed among group IV compared to all other groups. Egg mass laid by females of group I presented the maximum weight being $623.33 \mathrm{mg}$ which significantly decreased to $533.33,457.27$ and $343.75 \mathrm{mg}$ in groups II, III and IV, respectively. Fertility (weight of egg mass/weight of replete female) was reduced significantly $(\mathrm{P}<0.01)$ from 0.71 and 0.68 in groups I and II, respectively, which are insignificantly differ; to 0.59 and 0.52 in groups III and IV, respectively. On the other hand, the mean weight of one egg showed a diverse trend since it is increased significantally $(\mathrm{P}<0.01)$ from 0.06649 and $0.06670 \mathrm{mg}$ in control groups I and II respectively, to $0.06721 \mathrm{mg}$ in $\mathrm{SgAg}$-immunized group. Whereas, $\mathrm{MgAg}$ immunized group which is statistically similar to the Alum-inoculated and SgAg-immunized group, exhibited a significant increase when compared with the negative control since it was $0.06686 \mathrm{mg}$ [Table 3]. 
Table 2:- Effects of salivary gland and midgut antigens on oviposition and hatchability of female $H$. dromedarii.

\begin{tabular}{|c|c|c|c|c|}
\hline Biological parameter & Group I & Group II & Group III & Group IV \\
\hline Oviposition percent $\% \pm \mathrm{SE}$ & $\begin{array}{r}100.00 \pm \\
5.773^{\mathrm{a}}\end{array}$ & $\begin{array}{r}100.00 \pm \\
5.773^{\mathrm{a}}\end{array}$ & $\begin{array}{l}76.67 \pm \\
5.773^{b}\end{array}$ & $\begin{array}{l}60.00 \pm \\
5.773^{c}\end{array}$ \\
\hline $\begin{array}{l}\text { Preoviposition period (day) (Mean } \\
\pm \text { SE) }\end{array}$ & $\begin{array}{l}6.17 \pm \\
0.17^{\mathrm{a}} \\
\end{array}$ & $\begin{array}{r}6.27 \pm \\
0.15^{\mathrm{a}} \\
\end{array}$ & $\begin{array}{l}6.36 \pm \\
0.18^{a} \\
\end{array}$ & $\begin{array}{l}6.63 \pm \\
0.21^{\mathrm{a}} \\
\end{array}$ \\
\hline $\begin{array}{l}\text { Oviposition period (day) (Mean } \pm \\
\text { SE) }\end{array}$ & $\begin{array}{r}22.33 \pm \\
0.45^{b} \\
\end{array}$ & $\begin{array}{r}22.87 \pm \\
0.40^{\mathrm{b}} \\
\end{array}$ & $\begin{array}{c}23.55 \pm \\
0.47^{\mathrm{ab}} \\
\end{array}$ & $\begin{array}{c}24.62 \pm \\
0.55^{\mathrm{a}} \\
\end{array}$ \\
\hline No. of eggs (Mean \pm SE) & $\begin{array}{c}\text { 9373.67 } \pm \\
3^{4} 8.96^{\mathrm{a}}\end{array}$ & $\begin{array}{r}\text { 7993.53士 } \\
\text { 312.12 }^{\mathrm{b}}\end{array}$ & $\begin{array}{r}6838.27 \pm \\
364.48^{c}\end{array}$ & $\begin{array}{c}5114.25 \pm \\
427.39^{d}\end{array}$ \\
\hline $\begin{array}{l}\text { Prehatching period (day) (Mean } \pm \\
\text { SE) }\end{array}$ & $\begin{array}{c}22.17 \pm \\
0.38^{b}\end{array}$ & $\begin{array}{c}22.73 \pm \\
0.34^{\text {ab }}\end{array}$ & $\begin{array}{c}23.00 \pm \\
0.40^{\mathrm{ab}}\end{array}$ & $\begin{array}{r}23.50 \pm \\
0.47^{\mathrm{a}}\end{array}$ \\
\hline Hatching percentage $\% \pm \mathrm{SE}$ & $\begin{array}{c}96.83 \pm \\
0.46^{\mathrm{a}}\end{array}$ & $\begin{array}{c}94.07 \pm \\
0.41^{b}\end{array}$ & $\begin{array}{r}91.40 \pm \\
0.48^{\mathrm{c}}\end{array}$ & $\begin{array}{c}88.94 \pm \\
0.56^{d}\end{array}$ \\
\hline
\end{tabular}

Group I: Negative control, Group II: Alum-inoculated rabbits, Group III: MgAg-immunized rabbits and Group IV: SgAg-immunized

rabbits. Figures followed by the same letters are statistically similar $(\mathrm{p}>0.05)$; those followed by different letters are significantly different $(\mathrm{p}<0.05-\mathrm{p}<0.01)$.

Table 3:- Effects of salivary gland and midgut antigens on fertility of female $H$. dromedarii.

\begin{tabular}{|c|c|c|c|c|c|}
\hline \multicolumn{2}{|c|}{ Biological parameter } & Group I & Group II & Group III & Group IV \\
\hline \multicolumn{2}{|c|}{$\begin{array}{l}\text { Mean weight of replete female } \\
(\mathrm{mg})(\text { Mean } \pm \mathrm{SE})\end{array}$} & $\begin{array}{c}877.50 \pm \\
23.97^{\mathrm{a}} \\
\end{array}$ & $\begin{array}{c}782.67 \pm \\
21.44^{b} \\
\end{array}$ & $\begin{array}{r}754.55 \pm \\
25.03^{b} \\
\end{array}$ & $\begin{array}{r}651.25 \pm \\
29.35^{c} \\
\end{array}$ \\
\hline \multicolumn{2}{|c|}{$\begin{array}{l}\text { Mean weight of egg mass } \\
(\mathrm{mg})(\text { Mean } \pm \mathrm{SE})\end{array}$} & $\begin{array}{c}623.33 \pm \\
23.25^{\mathrm{a}}\end{array}$ & $\begin{array}{c}533.33 \pm \\
20.79^{b}\end{array}$ & $\begin{array}{c}457.27 \pm \\
24.28^{c} \\
\end{array}$ & $\begin{array}{r}343.75 \pm \\
28.47^{d}\end{array}$ \\
\hline \multirow[t]{2}{*}{ Fertility } & $\begin{array}{l}\text { Weight of egg mass }(\mathrm{mg}) / \\
\text { female weight }(\mathrm{mg})(\text { Mean } \pm \\
\text { SE) }\end{array}$ & $\begin{array}{l}0.71 \pm \\
0.01^{\mathrm{a}}\end{array}$ & $\begin{array}{l}0.68 \pm \\
0.01^{\mathrm{a}}\end{array}$ & $\begin{array}{l}0.59 \pm \\
0.01^{b}\end{array}$ & $\begin{array}{l}0.52 \pm \\
0.01^{c}\end{array}$ \\
\hline & $\begin{array}{l}\text { Weight of one egg }(\mathrm{mg}) \\
(\text { Mean } \pm \text { SE })\end{array}$ & $\begin{array}{l}0.06649 \pm \\
0.00012^{c}\end{array}$ & $\begin{array}{l}0.06670 \pm \\
0.00011^{b c}\end{array}$ & $\begin{array}{l}0.06686 \pm \\
0.00012^{\text {ba }}\end{array}$ & $\begin{array}{l}0.06721 \pm \\
0.00014^{\mathrm{a}}\end{array}$ \\
\hline
\end{tabular}

Group I: negative control, Group II: Alum-inoculated rabbits, Group III: MgAg-immunized rabbits and Group IV: Sg Ag-immunized rabbits.

Figures followed by the same letters are statistically similar $(\mathrm{p}>0.05)$; those followed by different letters are significantly different $(\mathrm{p}<0.05-\mathrm{p}<0.01)$.

The effect of the two prepared experimental vaccines on the reproductive index was determined by calculating the number of engorged female ticks (\%DT), the egg laying capacity (\%DO) and the vaccine efficacy [\%E]. The percentage DT of females dropped from SgAg-immunized rabbits was significantly reduced when compared with those dropped from MgAg-immunized ones which records $40 \%$ and 23\%, respectively. Additionally, females fed on $\mathrm{SgAg}$-immunized rabbits recorded $44.85 \% \mathrm{DO}$ which significantly reduced to $26.64 \% \mathrm{DO}$ for $\mathrm{MgAg}$-immunized group. The overall vaccine efficacy revealed that vaccination with $\mathrm{SgAg}$ was superior inducing impairment of feeding and reproductive performance. The efficacy percent equals to $67 \%$ and $43.7 \%$ for $\mathrm{SgAg}$ and $\mathrm{MgAg}$ respectively [Fig. 1]. 


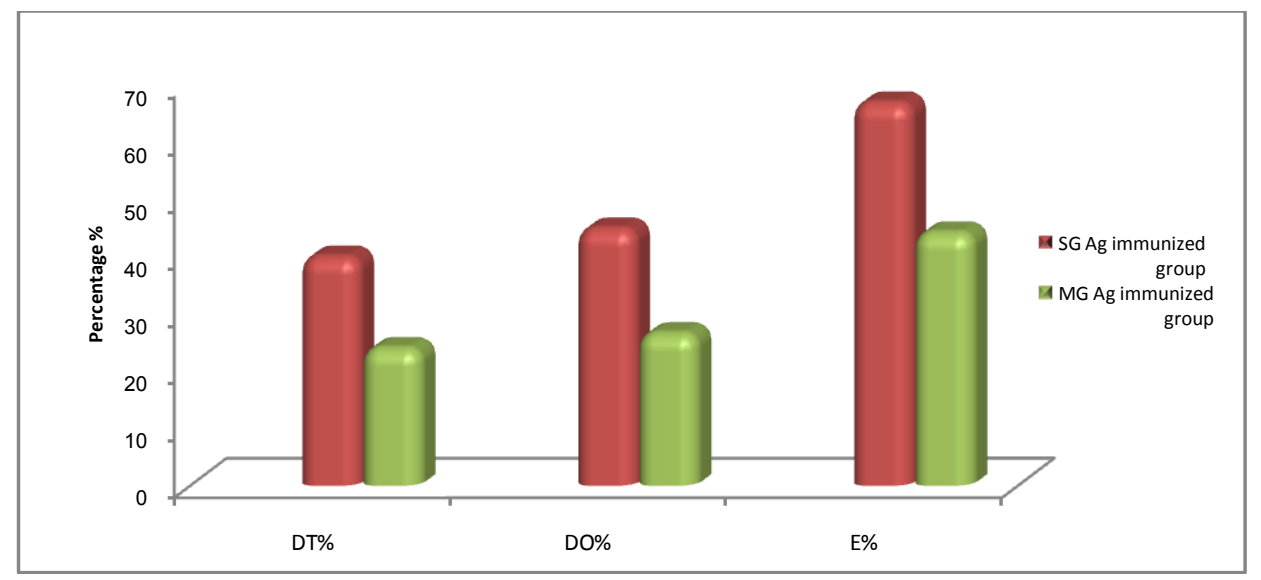

Fig. 1:- Effects of salivary gland and midgut antigens on the number of engorged females, the egg laying capacity and the overall vaccine efficacy.

The level of antibodies elicited post rabbit vaccination using $\mathrm{SgAg}$ and $\mathrm{MgAg}$ was monitored using ELISA. Specific IgG antibody titers were initially detected one week post the priming dose. This response was enhanced by subsequent boosting, rapidly increasing during the $2^{\text {nd }}$ week, following the second antigen inoculation. Antibody levels in MgAg-immunized rabbits reached its maximum on $28^{\text {th }}$ day post-primary inoculation, while those in $\mathrm{SgAg}$ immunized rabbits reached the maximum value one week post the third antigen dose (on day 36). No significant difference was observed in the antibody titers post challenge-infestation. The antibody levels remained similar and at high levels throughout the experiment. No significant differences between the antibody levels of the two antigens except on the days 21 and $28(\mathrm{P}<0.01)$. Also, no specific $\mathrm{IgG}$ antibodies were detected in the pre-immunization sera or sera from the negative control group.

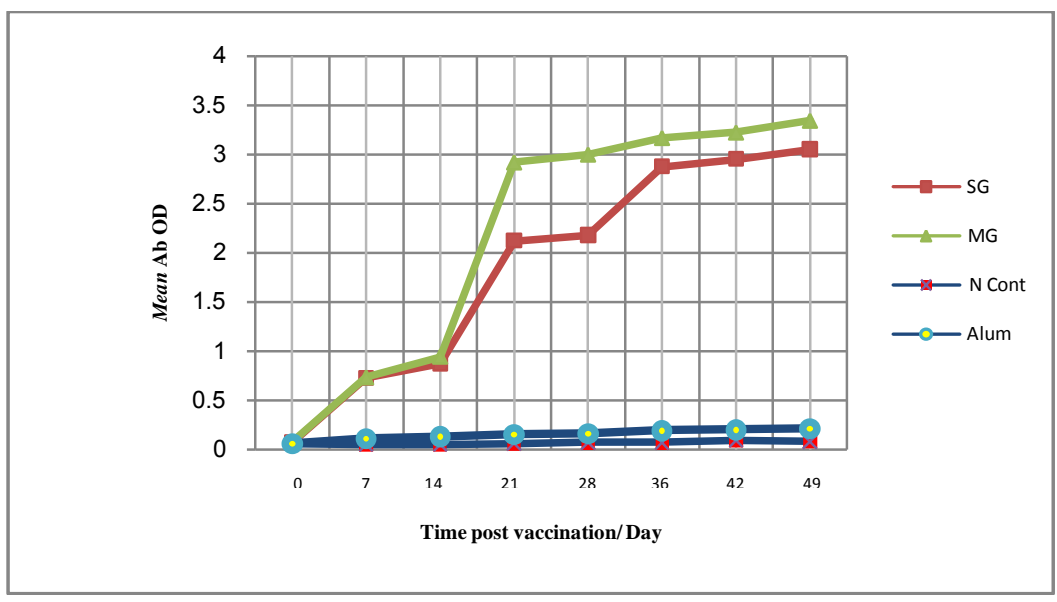

Fig. 2:- Comparative evaluation of immune response of rabbits post-vaccination with salivary gland and midgut experimental vaccines and Alum as adjuvant relative to time using ELISA.

Electrophoretic separation of $\mathrm{SgAg}$ and $\mathrm{MgAg}$ components was shown in [Fig. $3 \mathrm{~A} \& \mathrm{~B}$ ]. Approximately 12 polypeptide bands were resolved from $\mathrm{SgAg}$ as well as $\mathrm{MgAg}$. The respective molecular weights were 95.84, 83.41, 74.18, 54.4, 45.84, 36.26, 32.23, 25.74, 21.67, 19.55, 16.11 and $15.14 \mathrm{kDa}$ for $\mathrm{SgAg}$ [Fig. 3A] and 93.73, 81.99, 52.3, 42.4, 38.67, 30.03, 19.06, 17.89, 15.37, 14.41, 12.72 and $8.62 \mathrm{kDa}$ for MgAg [Fig. 3B]. [Fig. 4 ] showed the profile of reactive bands of $\mathrm{SgAg}$ and $\mathrm{MgAg}$ recognized by hyperimmune sera from immunized rabbits. $\mathrm{SgAg}$ included 7 reactive bands ranging in their molecular weights from 95.8 to $32.3 \mathrm{kDa}(95.84,83.41,74.18,54.4,45.84$, 36.26 and $32.23 \mathrm{kDa})$. Most of the 7 polypeptides are faintly stained and only two (95.84 and $54.4 \mathrm{kDa})$ have a moderate reaction. On the other hand, $\mathrm{MgAg}$ revealed 10 reactive bands ranging in their molecular weights from 93.7 to $8.6 \mathrm{kDa}(93.73,81.99,52.3,42.4,38.67,30.03,19.06,14.41,12.72$ and $8.62 \mathrm{kDa})$. However, polypeptides with the 93.73 and $42.4 \mathrm{kDa}$ have a strong reaction. Meanwhile, polypeptides with the 52.3, 38.67 and $8.62 \mathrm{kDa}$ 
exhibited a moderate reactions while the remaining polypeptides are faintly stained. No colour reaction was observed between hyperimmune sera collected from Alum-inoculated and negative control groups and tested antigens.
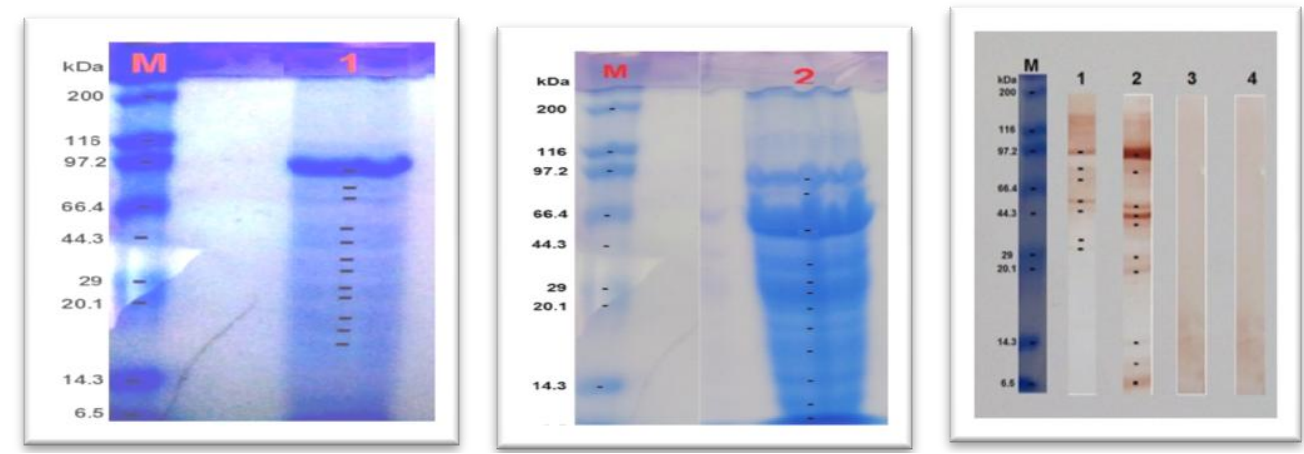

Fig. 3:- SDS-PAGE electrophoretic profile of salivary gland (A) and midgut (B) antigens derived from semi-fed female $H$. dromedarii. Lane (M): Molecular weight marker, Lane (1): Salivary gland antigen and Lane (2): Midgut antigen. [Fig.4]: Western blot analysis showing the reactive bands of salivary gland recognized by anti-SG Ag serum (1), Midgut antigen recognized by anti-MgAg serum (2) and $\mathrm{SgAg}$ and $\mathrm{MgAg}$ antigens recognized by pool of anti-Alum and negative control sera (3 and 4 respectively).

\section{Discussion:-}

Adult $H$. dromedarii as most ixodid ticks spend most of their life on the host. Therefore, the present study was directed to vaccinate hosts with experimentally prepared tick salivary gland and midgut homogenates to avoid severe drawbacks of using acaricides in controlling ticks, since the development of host immunity was considered as a new vision / alternative tick control measure. The effect of host vaccination was first investigated by Trager (1939b) and subsequently it was considerably dealt with. Data of the present investigation showed that immunization of hosts with tick $\mathrm{SgAg}$ and $\mathrm{MgAg}$ disrupt feeding and reproductive development of female $H$. dromedarii. According to Sran et al. (1996), it was reported that salivary gland antigens are involved in the acquisition of resistance to $H$. anatolicum as an important vector of bovine tropical theileriosis. The gut antigen also induced the best protection in terms of reduced feeding and reproductive performance of ticks (Kumar \& Kumar, 1995). The significantly decreased percentage of fed females observed in the present study may be attributed to the ability of ticks to manipulate the hemostatic effects of the mammalian hosts. Attenuation of fibrinolytic or antihemostatic agents of tick saliva causes disruption of blood flow and blocks successful feeding of the blood meal of ticks (Maritz-Olivier et al., 2007). Also, the moderate reduction in the feeding percentage of females fed on $\mathrm{SgAg}$ immunized rabbits was recorded, which was in agreement with the results obtained by Kumar and Kumar (1995) and El-Kelesh (2002) as they reported a significant reduction in the attachment rate of H. dromedarii using gut supernate and salivary gland antigens, respectively. Similar results were obtained by Sran et al. (1996) on immature $H$. anatolicum using salivary gland extract. Sahibi et al. (1997) found that immunization of cattle with salivary gland extract against $H$. marginatum reduced the percentage of attachment by $47 \%$, while intestinal extractgenerated immunity had no effect $(0 \%)$ on the attachment percentage. In contrary, Szabó and Bechara (1997) reported that the lowest tick recovery was obtained from guinea pigs immunized with gut extract and from dogs immunized with the gut extract emulsified in Freund's adjuvant instead of saponin adjuvant. Moreover, the attachment percent was found to be similar among rabbits immunized with both salivary gland and midgut antigens against Boophilus microplus, with no significant difference compared to control group (86.67\%, 83.34\% and 85\%, respectively) (Asif $\boldsymbol{e t}$ al., 2011). The variable reduction percentages may be attributed to the tick species, host variation and even variable tolerance among individuals of the same species. It was found that, rejection of large ticks represents a lower percentage than that of small ones as observed by Banerjee et al. (2003) who recorded $34 \%$ rejection against adult $H$. antolicum versus $87.8 \%$ rejection against the smaller adult Rhipicephaus sanguineus (Szabó and Bechara, 1997). The authors suggested that larger ticks are more tolerant. Tick evasion mechanisms might also affect coevolved host-parasite relationships when, even though there is an effective resistance to ticks, immunosuppressed state of hosts may prevail (Wikel and Allen, 1982); Willadsen et al., 1993). Another possible reason is the efficiency of Freund's adjuvant which is known to stimulate Th1 type immune response (Audibert and Lise, 1993) which may have a predominated effect. This suggestion was also demonstrated by Szabó and Bechara (1997) who reported that dogs immunized with Freund's adjuvant only, produced lower mean egg mass weight than ticks from dogs inoculated with gut extract and saponin. It seems generally that the effector arm of the immune 
response interfered with the fixation of the ticks on the host and also with their subsequent suction of blood. In the present study, $H$. dromedarii females fed on vaccinated hosts reacted to both antigens by expressing short feeding period with ingestion of small amounts of blood and consequently lower body weights. This shortening of the feeding time is also reported by Abdel-Shafy et al. (2008) using gut antigens and Sahibi et al. (1997) who concluded that stronger immunization using salivary gland antigens can probably inhibit feeding totally and subsequent transmission of tick-borne pathogens. On the other hand, Jittapalapong et al. (2000) reported that immunization of dogs using tick salivary gland extract significantly prolonged the feeding period of $R$. sanguineus females, suggesting a slower suction of blood. Impairment of tick feeding in terms of tick yield and engorgement weight observed from the present results was in agreement with the findings of kumar (1990) and Banerjee et al. (2003) against $H$. anatolicum, Kumar and Kumar (1995) and El-Kelesh (2002) against $H$. dromedarii, Sahibi et al. (1997) against $H$. marginatum, Szabó and Bechara, 1997 against $R$. sanguineus and Jittapalapong et al. (2004) against $B$. microplus. Retarded feeding or complete rejection of ticks from immunized hosts was attributed to the influence of anti-saliva response not to the response against gut components that have been regurgitated during blood meal (Connat, 1991). In the present study, the number of females that have the ability to oviposit was greatly reduced by $40 \%$ and $23 \%$ for $\mathrm{SgAg}$ - and MgAg-immunized groups, respectively, and those that did, took a considerably longer time to complete oviposition with no significant change in the pre-oviposition period. In ticks, the actual volume or weight of condensed blood meal exerts its effects on reproductive development (Diehl et al., 1982). However, at suboptimal levels, oogenesis may not be initiated or, if it begins, will not be sustained. A further general reduction in the number of eggs produced may be due to prolongation of the period between feeding and oviposition. In the present study, ticks fed on $\mathrm{SgAg}$ - and $\mathrm{MgAg}$-vaccinated rabbits and succeeded in laying eggs, produced few number that took longer time before the hatched larvae emerged when compared to control groups. The prehatching period of MgAg-immunized group was similar to that of the Alum-inoculated one but slightly longer than that of the negative control group. Meanwhile, the egg laying capacity, hatchability and fertility of both vaccinated groups were significantly reduced. Similar observations were also reported by Kumar and Kumar (1995), El-Kelesh (2002) and Abdel-Shafy et al. (2008) on H. dromedarii, Sahibi et al. (1997) on H. marginatum, Jittapalapong et al. (2000) on $R$. sanguineus and the same author et al. (2004) and Asif et al. (2011) on B. microplus. It seems clear that, the reduction in the production indices may be attributed simply to impairment in meal processing or to the host immune response which affects directly the physiology of ticks in some permanent way that persists even after the parasite detachment. Ben-Yakir et al. (1986) and Wang and Nuttall (1994) cleared that midgut is permeable to host immunoglobulins, and that these antibodies enter the tick hemolymph and can bind to antigens associated with other internal organs of the tick. These host immune effectors present in the blood meal not only destroying the candidate cells as the damage caused to the gut cells and leakage of gut contents into the haemocoel in response to immunization with gut antigens against B. microplus (Agbede and Kemp, 1986), but also could bind to antigens associated with the vital organs such as the reproductive organs and could have detrimental effects on the oogenesis and egg hatchability of ticks. This can be explained on the basis of the presence of common antigens in different organs of the ticks (Wang and Nuttal, 1999).

The drastic effects of immunizing hosts with $\mathrm{SgAg}$ - and $\mathrm{MgAg}$ on the feeding and reproductive performance of the tick $H$. dromedarii observed in the present study may based on the concept that ticks feeding on appropriately immunized hosts might ingest antibodies specific for target antigens within the tick. This suggests that these antibodies may apply their effect through certain routes, possibly the nervous system and specifically via the neuroendocrine or endocrine mechanism essential in the regulation of feeding and consequently oocyte differentiation and/or vitellogenesis (Pound \& Oliver, 1979). In the present study, a strong antibody response was rapidly detected in vaccinated rabbits. The immunogenic capacity of these antigens and their characterized specific proteins has been extensively documented through a high number of immunization trials (Sran et al. 1996; Jittapalapong et al. 2000; Trimnell et al., 2005; Prevot et al., 2007; Abdel-Shafy et al. 2008; Madani et al., 2008; Habeeb et al., 2009; Asif et al. 2011; Kumar et al., 2012; Jiang et al., 2014; Ali et al., 2015). Moreover, high antibody level was suggested to correlate with the protective efficacy against tick infestations (Willadsen, 2004). This protective efficacy was observed as a physical damage to ticks (Imamura et al., 2006) and as a reduction of the biotic potential (Barriga, 1999) which would likely result in progressive reduction of tick populations, while in turn can enhance reduction of acaricides use. Also, MgAg-immunized group had a slightly higher antibody titer than $\mathrm{SgAg}$-immunized one. In the present study, western blotting analysis revealed that $\mathrm{SgAg}$ and $\mathrm{MgAg}$ could induced polyclonal antibodies against the two Ags polypeptides, and $\mathrm{MgAg}$ was more immunogenic. This may be attributed to the gut proteins content that enhance random stimulation of immune system than that of the $\mathrm{SgAg}$, which was supported by the reactivity to 10 and 7 bands of proteins, respectively. The protective efficacy, impairment of feeding and reproduction were influenced by vaccination. This may be attributed 
to the different concentrations, antigens content and feeding duration. Also, the possible reasons could be due to some proteases are abundant in the various tissues of the tick and that they exist as multiple isoenzymes, therefore a high concentration of antibodies directed against them could be necessary to induce a significant injury to the tick (Imamura et al., 2009). Additionally, some saliva proteolytic enzyme inhibitors such as Iris was found to be upregulated during the blood meal and their concentration increased at the end of feeding (Leboulle et al., 2002) when tick ingest the great amount of blood (Sonenshine, 1991), suggesting its particular usefulness in this late feeding step as it could be ingested with the blood meal to the midgut and could facilitate both blood intake and protection of the midgut walls (Prevot et al., 2007). Kemp et al. (1989) suggested that B. microplus can, to a significant extent, repair immunologically induced damage to its gut. Perhaps the balance between the damage and repair will determine the outcome of vaccination, which may differ from species to species. The degree of damage and oviposition capacity may depends also on the amount of blood ingested, and hence the amount of antibodies developed post vaccination. Finally it can be concluded that experimentally immunization of rabbits with salivary gland extract of $H$. dromedarii homogenates effectively impaired tick feeding and reproduction much better than vaccination with midgut homogenate suggesting further investigations to characterize the protective antigens involved in the protection process.

\section{References:-}

1. Abdel-Shafy, S.; M.S. Mahmoud and M.M. Abdel-Aziz. 2008. Evaluation of crude and fractionated gut extract antigens for protection against camel tick Hyalomma dromedarii (Acari: Ixodidae). J. Entomol., 5(2): 91-102.

2. Agbede, R.I.S. and D.H. Kemp. 1986. Immunization of cattle against Boophilus microplus using extracts derived from adult female ticks: histopathology of ticks feeding on vaccinated cattle. Int. J. Parasitol. 16: 35-41.

3. Ali, A.; L.F. Parizi; M.G. Guizzo; L. Tirloni; A. Seixas; I.daS.Jr. Vaz and C. Termignoni. 2015. Immunoprotective potential of a Rhipicephalus (Boophilus) microplus metalloprotease. Vet. Parasitol., 207(12):107-14.

4. Allen, J.R. and S.J. Humphreys . 1979. Immunization of guinea pigs and cattle against ticks. Nature, 280 : 491 493.

5. Asif, M.; K. Saeed and K. Muhammad. 2011. Immune response and tick rejection pattern of midgut and salivary gland vaccines against locally prevalent Boophilus microplus ticks. J. Animal \& Plant Sci., 21(1): 1215 .

6. Audibert, T.F.M. and L.D. Lise. 1993. Adjuvants: current status, clinical perspectives and future prospects. Immunol. Today, 14: 281-284.

7. Banerjee, D.R.; R. Kumar; S. Kumar and P.P. Sengupta. 2003. Immunization of cross bred cattle (Bos indicus X Bos taurus) with fractionated midgut antigens against Hyalomma anatolicum anatolicum. Trop. Anim. Health Prod., 35: 509-519.

8. Barriga, O.O. 1999. Evidence and mechanisms of immunosuppression in tick infestations. Genet. Anal., 15: 139-142.

9. Ben-Yakir, D.; J.C. Fox; J.T. Homer and R.W. Barker. 1986. Quantitative studies of Host Immunoglobulin G Passage into the Haemocoel of the tick Amblyomma americanum and Dermacentor variabilis. In: Sauer, R.J. and J.A. Hair (Eds.), Morphology, Physiology and Behavioral Biology of Ticks. Chichester, UK: Ellis Horwood, pp: 329-339.

10. Berger, R.S.; J.C. Dutes and Y.S. Chow. 1971. Demonstration of a sex pheromone in three species of hard ticks. J. Med. Entomol., 8: 84-86.

11. Bhattacharyulu, Y.; R.P. Chaudhri and B.S. Gill. 1975. Transstadial transmission of Theileria annulata through common ixodid ticks infesting Indian cattle. Parasitol., 7: 1-7.

12. Brown, S.J. and P.W. Askenase. 1986. Amblyomma americanum: Physiochemical isolation of a protein derived from the tick salivary gland that is capable of inducing immune resistance in guinea pigs. Exp. Parasitol., 62: 40-50.

13. Connat, J.L. 1991. Demonstration of regurgitation of gut content during blood meals of the tick Ornithodoros moubata. Possible role in the transmission of pathogenic agents. Parasitol. Res., 77: 452-454.

14. de La Fuente, J. and K.M. Kocan. 2006. Strategies for development of vaccines for control of ixodid tick species. Parasite Immunol., 28: 275-283.

15. Diehl, P.A.; A. Aeschliman and F.D. Obenchain. 1982. Tick reproduction: oogenesis and oviposition. In: Obenchain F.D. and R. Galun (Eds.), Physiology of ticks. Pergamonn Press, Oxford, pp. 277-350.

16. El-Kelesh, E.A.M. 2002. Application of the Hyalomma dromedarii salivary gland epitopes for protection against camel ticks. Ph.D. thesis, Faculty of Veterinary Medicine, Cairo University, Egypt. 
17. Galaï, Y.; M. Canales; M. Ben-Saïd; M. Gharbi; M. Mhadhbi; M. Jedidi; J. de La Fuente and M.A. Darghouth. 2012. Efficacy of Hyalomma scupense (Hd86) antigen against Hyalomma excavatum and H. scupense tick infestations in cattle. Vaccine, 30: 7084-9.

18. Graf, J.F.; R. Gogolewski; N. Leach-Bing; A. Sabatini; B. Mento and E.L. Bordin. 2004. Tick control: an industry point of view. Parasitology, 129: S427-442.

19. Habeeb, S.M.; O.M. Kandil and A.H. El-Namaky. 2009. Evaluation of fractionated proteins extracted from different stages of Hyalomma dromedarii (Acari: Ixodidae) as a control agent against female ticks. Global Veterinaria, 3(2): 125-131.

20. Heller-Haupt, A.; L.K. Kagaruki and M.G.R. Varma. 1996. Resistance and cross-resistance in rabbits to adults of three species of African ticks (Acari: Ixodidae). Exp. App. Acarol., 20: 155-165.

21. Ibrahim, M.A.; A.H. Ghazy; T. Maharem and G.M. Khalil. 2001. Isolation and properties of two forms of thrombin inhibitor from the nymphs of the camel tick Hyalomma dromedarii (Acari: Ixodidae). Exp. App. Acarol., 25: 675-98

22. Imamura, S.; B. Namangala; T. Tajima; M.E. Tembo; J. Yasuda; K. Ohashi and M. Onuma. 2006. Two serine protease inhibitors (serpins) that induce a bovine protective immune response against Rhipicephalus appendiculatus ticks. Vaccine, 24(13): 2230-2237.

23. Imamura, S.; I.daS.Jr. Vaz; S. Konnai; S. Yamada; C. Nakajima; M. Onuma and K. Ohashi. 2009. Effect of vaccination with a recombinant metalloprotease from Haemaphysalis longicornis. Exp. Appl. Acarol. 48: 345358.

24. Jiang, X.; J. Gao; W. Wang; M. Xu; W. Li; M. Qi; C. Yang; L. Ji; D. Zhang; J. Luo and H. Yin. 2014. Molecular characterization of an alanine-, proline-, glycine-, threonine-, and serine-rich protein of the hard tick Haemaphysalis qinghaiensis and its effect as a vaccine against tick infestation in sheep. Ticks Tick Borne Dis., 5(1): 14-20.

25. Jittapalapong, S.; R.W. Stich; J.C. Gordon; T.E. Wittum and O.O. Barriga. 2000. Performance of female Rhipicephalus sanguineus (Acari: Ixodidae) fed on dogs exposed to multiple infestations or immunization with tick salivary gland or midgut tissues. J. Med. Entomol., 37: 601-611.

26. Jittapalapong, S.; W. Jansawan; A. Gingkaew; O.O. Barriga and R.W. Stich. 2004. Protection of dairy cows immunized with tick tissues against natural Boophilus microplus infestations in Thailand. Ann. N.Y. Acad. Sci., 1026: 289-297.

27. Kemp, D.H.; R.D. Pearson; J.M. Gough and P. Willadsen. 1989. Vaccination against Boophilus microplus: localization of antigens on tick gut cells and their interaction with the host immune system. Exp. App. Acarol. 7(1): 43-58.

28. Khalil, G.M.; D.E. Sonenshine; H.A. Hanafy and A.E. Abd-Elmonem. 1984. Juvenile hormone 1. Effects on the camel tick, Hyalomma dromedarii (Acari: Ixodidae). J. Med. Entomol., 21(5): 561-566.

29. Kumar, R. 1990. Studies on the immunological control of Boophilus microplus and Hyalomma anatolicum anatolicum on cross bred cattle. $\mathrm{PhD}$ thesis submitted to Punjab Agricultural University, Ludhiana, India.

30. Kumar, R. and R. Kumar. 1995. Artificial immunization of rabbits with Hyalomma dromedarii tick-derived midgut antigen. Exp. App. Acarol., 19: 319-324.

31. Laemmli, U.K. 1970. Cleavage of structural proteins during the assembly of the head Bacteriophage T4. Nature, 227: 680-685.

32. Leboulle, G.; M. Crippa; Y. Decrem; N. Mejri; M. Brossard; A. Bollen and E. Godfroid. 2002. Characterization of a novel salivary immunosuppressive protein from Ixodes ricinus ticks. J. Biol. Chem., 277(12): 10083-9.

33. Madani, R.; F. Golchinfar; A. Dadmehr and M. Abdigoudarzi. 2008. Preparation of antigens from midgut of Hyalomma anatolicum anatolicum and determining their immunoprotective effects. Archives of Razi Institute, 63(2): 47-52.

34. Manohar, G.S. and D.P. Banerjee. 1992. Effects of immunization of rabbits on establishment, survival, and reproductive biology of the tick Hyalomma anatolicum anatolicum. J. Parasitol., 78(1): 77-81.

35. Maritz-Olivier, C.; C. Stutzer; F. Jongejan; A.W. Neitz and A.R. Gaspar. 2007. Tick antihemostatics: targets for future vaccines and therapeutics. Trends Parasitol., 23: 397-407.

36. Mazyad, S.A.M. and S.A.A. Khalaf. 2002. Studies on Theileria and Babesia infecting line and slaughtered animals in Al-Arish and El-Hasanah, North Sinai governorate, Egypt. J. Egypt. Soc. Parasitol., 32: 601-610.

37. Mulenga, A.; C. Sugimoto; Y. Sako; K. Ohashi; A. Musoke; M. Shubash and M. Onuma. 1999. Molecular characterization of a Haemaphysalis longicornis tick salivary gland-associated 29-kilodalton protein and its effect as a vaccine against tick infestation in rabbits. Infect. Immun., 67: 1652-1658.

38. Pound, J.M. and Jr. J.H. Oliver. 1979. Juvenile hormone: evidence of its role in the reproduction of ticks. Science, 206: 355-357. 
39. Prevot, P.P.; B. Couvreur; V. Denis; M. Brossard; L. Vanhamme and E. Godfroid. 2007. Protective immunity against Ixodes ricinus induced by a salivary serpin. Vaccine, 25: 3284-3292.

40. Pruett, J.H. 1999. Immunological control of arthropod ectoparasites-a review. Int. J. Parasitol., 29: 25-32.

41. Roberts, L.S. and J. Janovy. 2005. Foundations of parasitology, $7^{\text {th }}$ edn. McGraw Hill, Boston, pp. 644-646.

42. Sahibi, H.; A. Rhalem and O.O. Barriga. 1997. Comparative immunizing power of infections, salivary extracts and intestinal extracts of Hyalomma marginatum marginatum in cattle. Vet. Parasitol., 68: 359-366.

43. SAS.2004. Statistical Analysis System Institute, SAS User Guide Statistics, SAS Institute Inc., Cary, NC.

44. Sonenshine, D.E. 1991. Biology of ticks, Vol. 1. Oxford: Oxford University Press.

45. Sran, H.S.; A.S. Grewal and J.K. Kondal. 1996. Enhanced immunity of Hyalomma anatolicum anatolicum ticks in cross-bred (Bos indicus x Bos taurus) calves using ascaris extract immunomodulator with the tick salivary gland extract antigens. Vet. Immunol. Immunopath., 51: 333-343.

46. Szabó, M.P.J. and G.H. Bechara. 1997. Immunization of dogs and guinea pigs against Rhipicephalus sanguineus ticks using gut extract. Vet. Parasitol., 68: 283-294.

47. Tellam, R.L.; D. Smith; D.H. Kemp and P. Willadsen. 1992. Vaccination against ticks. In: Yong, W.K., Animal Parasite Control Utilizing Biotechnology. CRC Press, Boca Raton, FL, pp. 303-331.

48. Trager, W. 1939a. Acquired immunity to ticks. J. Parasitol., 25: 57-81.

49. Trager, W. 1939b. Further observations on acquired immunity to the tick Dermacentor variabilis Say. J. Parasitol., 25:137-139.

50. Trimnell, A.R.; G.M. Davis; O. Lissina; R.S. Hails and P.A. Nuttall. 2005. A cross-reactive cement antigen is a candidate broad-spectrum tick vaccine. Vaccine, 23: 4329-4341.

51. Voller, A.; D.E. Bidwell and A. Bartlett. 1976. Enzyme immunoassays in diagnostic medicine. Bull. World Health Organ., 53: 55-65.

52. Wang, H. and P.A. Nuttall. 1994. Excretion of host immunoglobulin in tick saliva and detection of IgG-binding proteins in tick haemolymph and salivary glands. Parasitol., 109: 525-530.

53. Wang, H. and P.A. Nuttall. 1999. Immunoglobulin-binding proteins in ticks: new target for vaccine development against a blood-feeding parasite. Cell. Mol. Life Sci., 56 (3-4): 286-295.

54. Wikel, S.K. and J.R. Allen. 1982. Immunological basis of host resistance to ticks. In: Obenchain, F.D. and R. Galun (Eds.), Physiology of ticks. Pergamonn Press, Oxford, pp: 119-168.

55. Willadsen, P. 1987. Immunological approaches to the control of ticks. Internat. J. Parasitol., 17: 671-677.

56. Willadsen, P. 2004. Anti-tick vaccines. Parasitol., 129: 367-398.

57. Willadsen, P.; H. Inokuma and R.L. Kerlin. 1993. Effects of cattle ticks (Boophilus microplus) infestation on the bovine immune system. Vet. Parasitol., 47: 107-118. 